\title{
Examining Semantic Priming in a Delayed Naming Task
}

\author{
Karen Murphy ${ }^{1,2}$ \\ ${ }^{1}$ Applied Cognitive Neuroscience Research Unit, Behavioural Basis of Health, Griffith Health Institute, Australia, \\ Queensland, Australia \\ ${ }^{2}$ School of Applied Psychology, Griffith University, Queensland, Australia \\ Correspondence: Karen Murphy, Applied Cognitive Neuroscience Research Unit, Behavioural Basis of Health, \\ Griffith Health Institute, Griffith University Queensland, 4222 \& School of Applied Psychology, Griffith \\ University, Gold Coast campus, Queensland, 4222, Australia. Tel: 61-7-5552-8952. E-mail: \\ k.murphy@griffith.edu.au
}

$\begin{array}{lrr}\text { Received: January 23, } 2012 & \text { Accepted: March 6, } 2012 & \text { Published: June 1, } 2012 \\ \text { doi:10.5539/ijps.v4n2p198 } & \text { URL: http://dx.doi.org/10.5539/ijps.v4n2p198 }\end{array}$

\begin{abstract}
Semantic priming refers to the finding that a word response is facilitated if it is preceded by a related word compared to when it is preceded by an unrelated word. Research has shown that semantic priming effects still occur under task conditions which would permit ample time for the completion of word recognition processes prior to response production. This study sought to examine the impact of a related prime-target context on word production. Participants completed an immediate word naming task and a delayed word naming task. There was a semantic priming effect for the immediate naming task. For the delayed naming task semantic priming was only evident at the $500 \mathrm{~ms}$ cue delay. This suggests a limited time frame in which a semantic context is able to facilitate word production.
\end{abstract}

Keywords: semantic priming, delayed naming, immediate naming, word recognition

\section{Introduction}

Semantic priming refers to the finding that a response to a target word is facilitated if it is preceded by a related word, compared to when it is preceded by a completely unrelated word. For example, if the target word is bread, the response time to this item will be shorter if it is primed by butter, than chair. One of the earliest demonstrations that a related context may shorten response latencies was a study by Schaffer and Wallace (1969). Participants were required to decide if a pair of simultaneously presented words both represented living or nonliving things (semantic judgement task). Response times were shorter if the two words represented living things from the same semantic category (e.g., tulip-pansy), compared to if they represented living things from different semantic categories (e.g., tulip-zebra).

Consistent with this result is the seminal work of Meyer and colleagues (Meyer \& Schvaneveldt, 1971; Schvaneveldt \& Meyer, 1973; Meyer, Schvaneveldt \& Ruddy, 1975) who demonstrated semantic priming effects using a variety of word recognition tasks. Meyer and Schvaneveldt (1971) presented participants with a simultaneous pair of letter strings, and the participant's task was to decide if both items were words or nonwords (double lexical decision task). They used two variations of this task. In the first experiment, participants had to decide if both letter strings were words ("yes" response); in the second experiment the decision was "same" if both letter strings were either words or nonwords, and "different" if one item was a word and the other a nonword. In both experiments response latencies for word decisions were shorter if the two words were related compared to when the two words were unrelated. This work was subsequently extended by Schvaneveldt and Meyer (1973), using the simultaneous presentation of three centrally located letter strings. Word relatedness was manipulated so the stimulus display could consist of related words, unrelated words or nonwords or a combination of any of these three items. Participants were required to make a lexical decision on the basis of the lexicality of all three letter strings. Word responses were shorter when two of the three words were related compared to when all three words were unrelated.

Meyer, Schvaneveldt and Ruddy (1975, Experiment 1) demonstrated that semantic priming effects persisted when a single lexical decision task was used (i.e., on each trial just one word or nonword was presented). In their third experiment, participants either completed a single lexical decision task, or made a lexical decision response to the first item (prime) and named the second item (target) presented on each trial. Semantic priming effects 
were found to be consistent in magnitude across both the lexical decision and naming tasks. In summary, these early studies demonstrate that semantic priming is a robust phenomenon, apparent across naming, semantic categorisation and a variety of lexical decision tasks. Since this early work, semantic priming in both lexical decision and word naming tasks has been reported widely within the literature (for reviews see Lucas, 1999; McNamara, 2005; Neely, 1991).

Numerous accounts have been proposed to explain the occurrence of semantic priming and most attribute the locus of semantic priming to either lexical access or postlexical mechanisms. For example, the connectionist network (e.g., Cree, McRae \& McNorgan, 1999; Masson, 1991, 1995; McRae de Sa \& Seidenberg, 1997; Plaut, 1995) and spreading activation (e.g., Anderson, 1976, 1983; Collins \& Quillian, 1969; Collins \& Loftus, 1975; Kintsch, 1988; Neely, 1977; Posner \& Snyder, 1975) approaches adopt the notion that context facilitates lexical access. Similarly the expectancy generation (e.g., Becker, 1980) and plausibility checking (e.g., Norris, 1986) approaches explain context effects as enhancing lexical access, but through the involvement of strategic processes. Finally, semantic matching (e.g., Neely \& Keefe, 1989), and compound cue (e.g., Dosher \& Rosedale, 1989; McKoon \& Ratcliff, 1992; Ratcliff \& McKoon, 1988, 1994) approaches postulate that participants implement a post-lexical relatedness check based on semantic context to enhance the execution of their responses in lexical decision tasks.

Semantic priming has also been demonstrated for word naming experiments that allow ample time for the completion of lexical access prior to response production. Dallas and Merikle $(1976 \mathrm{a}, \mathrm{b})$ demonstrated semantic priming when participants were presented with a word pair for approximately one second and required to name the target word indicated by a locational cue (postcue task). Balota, Boland and Shields (1989, Experiment 2) also used a postcue task and found that pronunciation latencies and durations were shorter for related compared to unrelated words pairs, although the size of the priming effect for the latency data decreased as cue delay increased from $400 \mathrm{~ms}$ to $1400 \mathrm{~ms}$. More recently, Murphy (2011) and Murphy and Green (2011) replicated the occurrence of semantic priming effects under postcue task conditions.

The occurrence of semantic priming effects under postcue task conditions is a robust phenomenon that does not fit easily with current accounts of priming. Firstly the stimulus display duration in these experiments would have provided ample time for the recognition of both words prior to cue onset (word recognition takes less than 200 ms see Balota and Chumbley, 1985). Therefore the facilitation effect on word recognition (lexical access) for targets shown with a related compared to an unrelated prime word does not explain postcue task semantic priming. Secondly, although there was a long time interval between word presentation and cue onset in the postcue experiments, it is unlikely that strategic processes can account for this finding either. For example, expectancy generation mechanisms would be of little assistance in this task as both prime and target words were presented to the participant. Moreover, plausibility checking cannot account for these data either as this process operates in parallel with perceptual analysis at stage prior to conscious recognition of the words. In a postcue task participants must have consciously processed both words prior to cue onset to be able to produce a naming response. While it has been noted by a number of researchers that post-lexical mechanisms have minimal involvement in naming tasks (e.g., Balota \& Chumbley, 1984; Balota \& Lorch, 1986; Seidenberg, Waters, Sanders \& Langer, 1984), others have argued against this line of reasoning (Keefe \& Neely, 1990). If one was to adopt the logic that post-lexical mechanisms may be operational in the postcue task it is unclear as to how they would be able to account for context facilitation effects. That is, it is unlikely that either semantic matching or cue familiarity of prime and target would offer any assistance in the execution of a naming response. Even if the compound cue approach is coupled with the extension to naming performance (see Humphreys, Wiles \& Bain, 1993), it is unclear why after a long cue delay there should still be less activity or greater noise for unrelated compared to related items in the intersecting item set from which the response is produced.

One possible explanation for the occurrence of semantic priming effects in a postcue task derives from research relating to the Stroop Interference effect (Stroop, 1935). The Stroop Interference effect refers to the well established finding that response times to identify the ink colour of a word are longer if there is a mismatch between the ink colour and the word name than when identifying a coloured patch or when the ink and colour word name match. Sternberg (1969) and Lupker and Katz (1981) suggested that the Stroop interference effect could have occurred at four possible stages: the input stage (perceptual analysis of the stimulus), the decision stage, the response selection stage, or the response output stage. More recently it has been proposed that the Stroop effect is attributable to either the response selection or output stages due to the fact that smaller interference effects are observed in manual response tasks compared to naming tasks (La Heij, 1988; La Heij, Van der Heijden \& Schreuder, 1985). This idea is consistent with Humphreys, Lloyd-Jones and Fias (1995) who proposed that the occurrence of semantic priming in a postcue task was due to a related context influencing the 
name retrieval stage. However in a postcue task there are two processing stages that must be completed to allow response production. The first is the response selection stage once the cue has been presented (e.g., decide which word to say aloud). The second is the actual output stage where the word is said aloud. It is therefore possible that postcue task priming effects could result from either of these stages. The aim of this study is to examine the impact of a related compared to unrelated prime-target context on a word naming task that allows the completion of all stages of stimulus processing except for the response output. To this end this study will use a delayed naming task. In a delayed naming task participants are presented with the to-be-named word and have enough time to prepare the pronunciation of the word prior to the onset of a cue requiring them to name the word aloud. At cue delays that allow sufficient time for the completion of word recognition prior to cue onset, any effect of a related context must be on processes that occur after recognition is complete (e.g., response output).

The delayed naming task has been used previously to examine the impact of word frequency and a related context on word naming. Balota and Chumbley (1985) investigated the impact of word frequency on word pronunciation using a delayed naming task with variable cue delays. They found that naming latencies were longer for low compared to high frequency words even at cue delays of $1400 \mathrm{~ms}$ and thus word frequency affected processes that occurred after word recognition such as word pronunciation. Balota et al. (1989) used a variant of the delayed naming task to examine the impact of a related context on word naming (Experiment 1). In this task participants were presented with the to-be-named target word and after a delay period the prime cue appeared indicating to name the target word (first word) aloud. The cue was a row of Xs (neutral) or a word unrelated to the target or a word that was related to the target. The time intervals between the target and cue (prime) were 150, 400, 650, 900 and $1150 \mathrm{~ms}$ and there was no semantic priming effect for the latency data at any cue delay. Naming durations (how long it took to pronounce the target word) were shorter for targets presented with a related prime (cue) compared to an unrelated prime (cue) at the 400 and $650 \mathrm{~ms}$ cue delays. One possible explanation for the lack of semantic priming for the latency data in the delayed naming task could be that the use of a related word as a cue actually interfered with response production (due to competition within the speech output stage) and eliminated any priming effect compared to when both words were unrelated. This study sought to overcome this issue by using a standard version of the delayed naming task to examine the effect of a related prime-target context on word naming. By using a naming task that only assesses the production of a naming response without a decision stage (as the postcue task requires) this would shed light on the potential locus of semantic priming effects in a postcue task (e.g., response decision or production). Hence if semantic priming occurs in the delayed naming task then this would suggest that at least part of the postcue task priming effects could be accounted for at the word pronunciation stage.

\section{Method}

\subsection{Participants}

Forty-four (35 female) introductory psychology course students aged 18 to 50 years $(M=23.80, S D=7.18)$ voluntarily completed this experiment in return for course credit. All participants were native English speakers, with normal or corrected-to-normal vision. Participants provided written informed consent prior to taking part in this study.

\subsection{Stimuli}

A total of 440 prime-target word pairs were used as stimuli in this experiment. Words ranged from 2 to 8 letters in length. There were 220 related prime-target word pairs taken from the Edinburgh Associative Thesaurus (CSID, 1996). All prime-target word pairs had an association value between 51 and $90 \%(M=63.12 \%, S D=$ 8.88 , CSID, 1996). This means that when presented with the prime word at least $51 \%$ of respondents produced the target word as the first word that came to mind. Words within each prime-target pair were also categorically related. The word pairs for the unrelated condition were obtained by reassigning items from the related word pairs with another word from the stimulus set. This resulted in a set of 220 word pairs that were not semantically or associatively related.

To avoid repetition priming, participants were only presented with a prime or target word once. Therefore, half the prime-target pairs were assigned to the related condition and the other half of the prime-target pairs to the unrelated condition. Condition assignment was reversed for half of the participants, so that equally often a prime-target pairs appeared in both the related and unrelated conditions. Each prime-target pairing was rotated across all possible combination of related and unrelated conditions and cue delay conditions (immediate or delayed naming task) creating 22 versions of the experiment. Across each condition both the prime and the target words were matched on word frequency (Baayen, Piepenbrock \& Van Rijn, 1993), Neighbourhood size (Baayen et al., 1993), number of letters and association indices (CSID, 1996) to ensure that experimental version did not 
affect any priming effects.

\subsection{Apparatus}

Stimuli were presented on a Hewlett Packard Ultra VGA 1024 computer monitor in lowercase white font on a black background, using the DMDX display system (Forster \& Forster, 2003) run by a Hewlett Packard Intel Pentium II computer. Participants were seated $60 \mathrm{~cm}$ away from the computer screen so that each word subtended between $0.35^{\circ}$ to $2.24^{\circ}$ wide and $0.35^{\circ}$ to $0.40^{\circ}$ high of visual angle.

\subsection{Procedure}

In the immediate naming task each trial began with a central fixation point displayed for $500 \mathrm{~ms}$. After a $100 \mathrm{~ms}$ blank screen the prime word appeared for $150 \mathrm{~ms}$ followed by a $550 \mathrm{~ms}$ blank screen and then the target word was presented for $500 \mathrm{~ms}$. Participants were instructed that two words would appear sequentially on the computer screen and that they should read the first word silently to themselves and then say aloud the second word as soon as it appeared on the screen. Participants completed 20 practice trials. The word pairs used in the practice and filler trials (see below) were a combination of related and unrelated word pairs that were not used in the actual experiment. In the immediate naming task the practice trials were followed by a single block of 5 filler trials (trials placed at the start of the block that were not used as part of the data collection) and 20 experimental trials (10 trials in a related context and 10 trials in an unrelated context). Participants were not informed about the nature of the filler trials.

In the delayed naming task each trial commenced with a $500 \mathrm{~ms}$ presentation of the fixation cross, followed by a blank screen for $100 \mathrm{~ms}$. The first word was presented for $150 \mathrm{~ms}$ followed by a $550 \mathrm{~ms}$ of blank screen and the target word for $500 \mathrm{~ms}$. The cue was then presented after the target word at one of 10 delay times $(250,500,750$, $1000,1250,1500,1750,2000,2250$ and $2500 \mathrm{~ms}$ delay times). Participants were informed that on each trial they would briefly see the first word that should be read silently and after a short delay a second word would appear which also should also be read silently. Once the cue (++++++++) appeared on the screen they should say aloud the second word as soon as possible. In the delayed naming task participants completed 20 practice trials and four blocks of experimental trials each containing 5 filler trials and 50 experimental trials. Within each of the four blocks of experimental trials, half the targets were presented in a related context and the other half in an unrelated context. Each block of trials contained a random range of cue delay conditions.

For both tasks the inter-trial interval was approximately one second. The experimenter manually recorded the accuracy of the pronunciation responses. Pronunciation latencies were recorded from cue onset until the participant response triggered the voice key activation. Task order was counter-balanced across participants. Both tasks were completed within a one hour time period.

\subsection{Design}

For both the immediate and delayed naming tasks the dependent variables were errors (\%) and naming latencies (ms) from target or cue onset respectively until the participant began to say aloud the target word. In the immediate naming task, the within subjects independent variable was prime-target context with 2 levels, related or unrelated. In the delayed naming task there were two within subjects independent variables, prime-target context as for the immediate naming task and cue delay with 10 levels $(250,500,750,1000,1250,1500,1750$, $2000,2250$ and $2500 \mathrm{~ms})$.

\section{Results}

Prior to the statistical analysis for the naming latency data, items on which participant errors or aberrant responses occurred were removed along with the matched item from the data set. For the immediate naming task a lower level cutoff of $50 \mathrm{~ms}$ was employed to eliminate any extremely short response latencies due to aberrant activation of the voice key. No lower level cutoff was used for the delayed naming task as very short latencies were possible within this task. Analysis for naming latency data was conducted using a related samples t-test for the immediate naming task and a 2 (prime-target context) x 10 (cue delay) Repeated Measures ANOVA for the delayed naming task. As is evident in Table 1 there were very few errors in any condition therefore no statistical analysis was conducted in these data.

Importantly there was a robust $16 \mathrm{~ms}$ priming effect for the latency data in the immediate naming task (related $\mathrm{M}$ $=454 \mathrm{~ms}, \mathrm{SE}=8.48$ : unrelated $\mathrm{M}=470 \mathrm{~ms}, \mathrm{SE}=9.57), \mathrm{t}(43)=-3.04, \mathrm{p}=.004$. A sign test was run to confirm that this priming effect could not be explained by a few participants with very large priming effects. This analysis revealed that the majority of participants $(69.76 \%)$ demonstrated a priming effect in the immediate naming task $(\mathrm{p}=.007)$. (Immediate naming task errors related $\mathrm{M}=0.23 \%, \mathrm{SE}=0.23$ : unrelated $\mathrm{M}=0.23 \%$, SE $=0.23$ ). 
Table 1. Mean latencies (ms) and errors (\%) for the delayed naming task for the related and unrelated prime-target contexts

\begin{tabular}{|c|c|c|c|c|c|}
\hline \multirow[b]{3}{*}{ Cue Delay (ms) } & \multicolumn{3}{|c|}{ Naming Latencies (ms) (SE) } & \multicolumn{2}{|c|}{ Errors (\%) (SE) } \\
\hline & \multicolumn{3}{|c|}{ Prime-Target Context } & \multicolumn{2}{|c|}{ Prime-Target Context } \\
\hline & Related & Unrelated & Priming & Related & Unrelated \\
\hline 250 & $465(13.39)$ & $470(13.68)$ & 5 & $0.91(0.44)$ & $0.68(0.38)$ \\
\hline 500 & $407(10.80)$ & $425(11.93)$ & 18 & $0.91(0.44)$ & $0.23(0.23)$ \\
\hline 750 & $388(11.30)$ & $395(12.61)$ & 7 & $0.23(0.23)$ & $0.68(0.50)$ \\
\hline 1000 & $375(10.66)$ & $376(9.99)$ & 1 & $0.46(0.32)$ & $0.23(0.23)$ \\
\hline 1250 & $365(10.19)$ & $367(10.50)$ & 2 & $0.23(0.23)$ & $0.46(0.32)$ \\
\hline 1500 & $360(10.69)$ & $362(10.43)$ & 2 & $0.46(0.32)$ & $0.68(0.38)$ \\
\hline 1750 & $354(8.89)$ & $357(10.26)$ & 3 & $0.46(0.32)$ & $0.23(0.23)$ \\
\hline 2000 & $358(10.72)$ & $356(9.44)$ & -2 & $0.91(0.44)$ & $0.91(0.44)$ \\
\hline 2250 & $349(9.44)$ & $353(9.89)$ & 4 & $0.68(0.38)$ & $0.91(0.44)$ \\
\hline 2500 & $355(9.18)$ & $357(9.54)$ & 2 & $1.13(0.58)$ & $0.00(0.00)$ \\
\hline
\end{tabular}

For the delayed naming task there was a significant effect of cue delay with naming latencies becoming shorter with longer cue delays, $F(9,387)=112.55, p<.0005, \eta_{\mathrm{p}}{ }^{2}=.72$. Naming latencies were shorter for targets shown in the related than unrelated prime-target contexts, $F(1,43)=6.89, p=.012, \eta_{\mathrm{p}}{ }^{2}=.14$. The interaction between cue delayed and prime-target context was not significant, $F(9,387)=0.88, p=.542, \quad \eta_{\mathrm{p}}{ }^{2}=.02$. See Table 1 for relevant descriptive statistics. Planned comparisons were run to confirm that there were in fact consistent priming effects at each cue delay. These comparisons showed that the only significant priming effect was at the $500 \mathrm{~ms}$ cue delay, $F(1,43)=6.89, p=.012$. A sign test was run at this cue delay interval to ensure this significant effect could not be explained by a few participants showing extremely large priming effects. The sign test revealed that the majority of participants $(65.91 \%)$ showed a priming effect at the $500 \mathrm{~ms}$ cue delay interval $(p=.025)$.

\section{Discussion}

There was a semantic priming effect in the immediate naming task and the sign test verified that this was not due to a few participants with very large priming effects. The occurrence of semantic priming in the immediate naming task is consistent with many other studies in this area (e.g., Lupker, 1984; Perea \& Gotor, 1997; Seidenberg et al, 1984), and has important implications for the potential to find a semantic priming effect in the delayed naming task. The prime-target word pairs were rotated across 22 versions of the two naming tasks to ensure that each prime-target word pair appeared at each cue delay in both the related and unrelated contexts. Hence the same stimuli were used in both the immediate and delayed naming tasks. Thus the delayed naming task had the potential to demonstrate a semantic priming effect through inclusion of stimuli shown to produce priming under immediate response conditions.

In the delayed naming task naming latencies became shorter as the length of the cue delay increased. This indicates that participants were able to use the increased time between the presentation of the target word and the onset of the cue to more fully prepare their naming response. This reduction in latency with increasing cue delay is consistent with results of Balota and Chumbley's (1985 Experiment 1) delayed naming task investigating the impact of word frequency on word naming and Balota et al.'s (1989 Experiment 1) delayed naming experiment examining the impact of a semantic context on word production.

Overall there was a priming effect for the delayed naming task. However the planned comparisons showed that there was only priming at the $500 \mathrm{~ms}$ cue delay. The occurrence of a priming effect at the $500 \mathrm{~ms}$ cue delay and not the $250 \mathrm{~ms}$ cue delay too may seem unusual. However, it is possible that at the $250 \mathrm{~ms}$ cue delay participants were still preparing their response when cue onset occurred. For example as participants were instructed to read each word silently and target words were displayed for $500 \mathrm{~ms}$ it is possible that participants took their time to compute their response output once the target appeared. It may have even been the case that participants took a strategic approach to start the preparation of output once the word was removed from the screen as cue onset would then follow. Thus at the $250 \mathrm{~ms}$ cue delay, the cue interfered with the response preparation eliminating 
any priming effect. This idea is consistent with the lack of priming reported by Balota et al. (1989) for naming duration data at the $150 \mathrm{~ms}$ cue delay where the descriptive statistics showed a trend towards longer latencies for targets shown with a related than an unrelated cue. At cue delays of $750 \mathrm{~ms}$ or longer any effect of a related prime-target context on word naming had dissipated. The occurrence of a semantic priming effect at the $500 \mathrm{~ms}$ cue delay is consistent with Balota et al. (1989), who reported naming duration priming at cue delays of 400 and $650 \mathrm{~ms}$ only. Thus it appears that semantic priming within a delayed naming task is limited to delays of approximately $500 \mathrm{~ms}$. This suggests that at least part of the impact of a related context in a postcue task may arise from the effect of context on naming response production.

The time interval between the onset of the prime word and the onset of the target word was $600 \mathrm{~ms}$ for all cue delays in this experiment. The time intervals between the target and prime words in the Balota et al. (1989) study were 400 and $650 \mathrm{~ms}$ where priming effects were evident for the naming duration data. Thus it appears that the semantic priming effects observed in a delayed naming task are the result of the operation of controlled or strategic processes. Future studies should use a short interval ( $250 \mathrm{~ms}$ or less) and a long interval (e.g., $500 \mathrm{~ms})$ between the onset of the prime and the onset of the target word to examine the impact of automatic and controlled semantic priming effects in a delayed naming task.

One possible limitation of the current study is that the longer cue delays (e.g., $2000 \mathrm{~ms}$ ) allowed participants to rehearse their naming response more times than the short cue delays (e.g., $500 \mathrm{~ms}$ or less). This difference in rehearsal frequency may have minimised any naming latency differences between the related and unrelated prime-target contexts as previous work examining word frequency has shown an effect of rehearsal in a delayed naming task (Rossmeissl \& Theios, 1982). That is while there may have been genuine differences in latency between targets shown in related and unrelated contexts this benefit was negated by word rehearsal. Future experiments could use articulatory suppression to prevent rehearsal during the cue delay time.

The current study showed semantic priming for an immediate naming task and for the 500 ms cue delay interval in the delayed naming task. This result suggests that semantic priming in a postcue task may partly be due to relatedness exerting an effect on response production. However further research is required in this area to fully understand how priming occurs in both delayed naming and postcue tasks. For example, examining the relative contributions of automatic and controlled processes and target rehearsal on these priming effects would further assist our understanding in this area of word recognition.

\section{References}

Anderson, J. R. (1976). Language, memory and thought. Hillsdale, NJ: Lawrence Erlbaum Associates.

Anderson, J. R. (1983). The architecture of cognition. Cambridge, MA: Havard University Press.

Baayen, R. H., Piepenbrock, R., \& VanRijn, H. (1993). CELEX Lexical Database. Linguistic Data Consortium, University of Pennsylvania: Philladelphia, USA.

Balota, D. A., Boland, J. E., \& Shields, L. W. (1989). Priming in pronunciation: beyond pattern recognition and onset latency. Journal of Memory and Language, 28, 14-36. http://dx.doi.org/10.1016/0749-596X(89)90026-0

Balota, D. A., \& Chumbley, J. I. (1985). The locus of word-frequency effects in the pronunciation task: Lexical access and/or production? Journal of Memory and Language, 24, 89-106. http://dx.doi.org/10.1016/0749-596X(85)90017-8

Balota, D. A., \& Lorch, R. F. (1986). Depth of automatic spreading activation: Mediated priming effects in pronunciation but not in lexical decision. Journal of Experimental Psychology: Learning, Memory and Cognition, 12, 336-345. http://dx.doi.org/10.1037/0278-7393.12.3.336

Becker, C. A. (1980). Semantic context effects is visual word recognition: An analysis of semantic strategies. Memory and Cognition, 8, 493-512. http://dx.doi.org/10.3758/BF03213769

Collins, A. M., \& Loftus, E. F. (1975). A spreading-activation theory of semantic processing. Psychological Review, 82, 407-428. http://dx.doi.org/10.1037/0033-295X.82.6.407

Collins, A. M., \& Quillian, M. R. (1969). Retrieval time from semantic memory. Journal of Verbal Learning and Verbal Behaviour, 8, 240-247. http://dx.doi.org/10.1016/S0022-5371(69)80069-1

Computing and Information Systems Department (CSID) (1996). Edinburgh Associative Thesaurus. Rutherford $\begin{array}{llll}\text { Appleton } & \text { Laboratory } & \text { RK. } & \text { from }\end{array}$ http://www.speech.cs.cmu.edu/comp.speech/Section1/Lexical/eat.html 
Cree, G., S., McRae, K., \& McNorgan, C. (1999). An Attractor Model of Lexical Conceptual Processing: Simulating Semantic priming. Cognitive Science, 23, 371-390. http://dx.doi.org/10.1207/s15516709 $\operatorname{cog} 2303 \_4$

Dallas, M., \& Merikle, P. M. (1976a). Semantic processing of non-attended visual information. Canadian Journal of Psychology, 30, 15-21. http://dx.doi.org/10.1037/h0082040

Dallas, M., \& Merikle, P. M. (1976b). Response processes and semantic-context effects. Bulletin of the Psychonomic Society, 8, 441-444.

Dosher, B. A., \& Rosedale, G. (1989). Integrated retrieval cues as a mechanism for priming in retrieval from memory. Journal of Experimental Psychology: General, 118, 191-211. http://dx.doi.org/10.1037/0096-3445.118.2.191

Forster, K. I., \& Forster, J. C. (2003). DMDX: A windows display program with millisecond accuracy. Behavior Research Methods, Instruments, and Computers, 35, 116-124. http://dx.doi.org/10.3758/BF03195503

Humphreys, G. W., Lloyd-Jones, T., \& Fias, W. (1995). Semantic interference effects on naming using a postcue procedure: Tapping the links between semantics and phonology with pictures and words. Journal of Experimental Psychology: Human Perception and Performance, 21, 961-980.

Humphreys, M. S., Wiles, J., \& Bain, J. D. (1993). Memory retrieval with two cues: Think of intersecting sets. In: In D. E. Meyer \& S. Kornblum (Eds.), Attention and performance XIV: A silver jubilee (pp. 489-507). Hillsdale, NJ: Erlbaum.

Keefe, D. E., \& Neely, J. H. (1990). Semantic priming in the pronunciation task: The role of prospective prime-generated expectancies. Memory and Cognition, 18, 289-298. http://dx.doi.org/10.3758/BF03213882

Kintsch, W. (1988). The role of knowledge in discourse comprehension: A construction integration model. Psychological Review, 95, 163-182. http://dx.doi.org/10.1037/0033-295X.95.2.163

La Heij, W. (1988). Components of Stroop-like interference in picture naming. Memory and Cognition, 16, 400-410. http://dx.doi.org/10.3758/BF03214220

La Heij, W., Van der Heijden, A., \& Schreuder, R. (1985). Semantic priming and Stroop-like interference in word-naming tasks. Journal of Experimental Psychology: Human Perception and Performance, 11, 62-80. http://dx.doi.org/10.1037/0096-1523.11.1.62

Lucas, M. (1999). Context effects in lexical access: A meta-analysis. Memory and Cognition, 27, 385-398. http://dx.doi.org/10.3758/BF03211535

Lupker, S. J. (1984). Semantic priming without association: A second look. Journal of Verbal Learning and Verbal Behavior, 23, 709-733. http://dx.doi.org/10.1016/S0022-5371(84)90434-1

Lupker, S. J., \& Katz, A. N. (1981). Input, decision, and response factors in picture-word interference. Journal of Experimental Psychology: Human Learning and Memory, 7, 269-282. http://dx.doi.org/10.1037/0278-7393.7.4.269

Masson, M. E. J. (1991). A distributed memory model of context effects in word identification. In Besner, D \& Humphreys, G. W. (Eds.), Basic processes in reading: Visual word recognition. (pp. 233-263). Hillsdale, New Jersey: Erlbaum Associates.

Masson. M. E. J. (1995). A distributed memory model of semantic priming. Journal of Experimental Psychology: Human Perception and Performance, 21, 3- 23.

McKoon, G., \& Ratcliff, R. (1992). Spreading activation versus compound cue accounts of priming: Mediated priming revisited. Journal of Experimental Psychology: Learning, Memory and Cognition, 18, 1155-1172. http://dx.doi.org/10.1037/0278-7393.18.6.1155

McNamara, T. P. (2005). Semantic priming: Perspectives from memory and word recognition. New York: Psychology Press. http://dx.doi.org/10.4324/9780203338001

McRae, K, De Sa, V. R., \& Seidenberg, M. (1997). On the scope of featural representations of word meaning. Journal of Experimental Psychology: General, 126, 99-130. http://dx.doi.org/10.1037/0096-3445.126.2.99

Meyer, D. E., \& Schvaneveldt, R. W. (1971). Facilitation in recognizing pairs of words: evidence of a dependence between retrieval operations. Journal of Experimental Psychology: General, 90, 227-234. http://dx.doi.org/10.1037/h0031564

Meyer, D. E., Schvaneveldt, R. W., \& Ruddy, M. G. (1975). Loci of contextual effects on visual word recognition. 
In S. Dornic (Eds.), Attention and Performance VI (Vol. 5, pp. 98-118). New York: Lawrence Erlbaum Associates.

Murphy, K. (2011). Semantic priming occurs for word but not location pronunciation in the postcue task. Cognitive Processing, 12, 197-201. http://dx.doi.org/10.1007/s10339-010-0381-9

Murphy, K., \& Green, L. (2011). The effect of target context and cue type in a postcue word pronunciation task. Advances in Cognitive Psychology, 7, 39-48. http://dx.doi.org/10.2478/v10053-008-0086-0

Neely J. H. (1977). Semantic priming and retrieval from lexical memory: Roles of inhibitionless spreading activation and limited-capacity attention. Journal of Experimental Psychology: General, 106, 226-254. http://dx.doi.org/10.1037/0096-3445.106.3.226

Neely, J. H., \& Keefe, D. E. (1989). Semantic context effects on visual word processing: A hybrid prospective/retrospective theory. In G. H. Bower (Eds.), The psychology of learning and motivation: Advances in research and theory, Vol 24 (pp. 207-248). New York: Academic Press.

Neely, J. H. (1991). Semantic priming effects in visual word recognition: A selective review of current findings and theories. In D. Besner \& G. W. Humphreys (Eds.), Basic processes in reading: Visual word recognition (pp. 264-336). Hillsdale, J. N.: Erlbaum Associates.

Norris, D. (1986). Word recognition: Context effects without priming. Cognition, 22, 93-136. http://dx.doi.org/10.1016/S0010-0277(86)90001-6

Perea, M., \& Gotor, A. (1997). Associative and semantic priming effects occur at very short stimulus-onset asynchronies in lexical decision and naming. Cognition, 62, 223-240. http://dx.doi.org/10.1016/S0010-0277(96)00782-2

Plaut, D. C. (1995). Sematic and associative priming in a distributed attractor network. In Proceedings of the 17th Annual Conference of the Cognitive Science Society. Hillsdale, NJ: Lawrence Erlbaum Associates. pp. $37-42$.

Posner, M. I., \& Snyder, C. R. R. (1975). Facilitation and inhibition in the processing of signals. In Rabbitt, P. M. A., \& Dornic, S. (Eds,), Attention and Performance V. Academic Press Inc. London, (pp. 669-682).

Ratcliff, R., \& McKoon, G. (1988). A retrieval theory of priming in memory. Psychological Review, 95, 385-408. http://dx.doi.org/10.1037/0033-295X.95.3.385

Ratcliff, R., \& McKoon, G. (1994). Sentential context and on-line lexical decision. Journal of Experimental Psychology: Learning, Memory and Cognition, 20, 1239-1243. http://dx.doi.org/10.1037/0278-7393.20.5.1239

Rossmeissl, P. G., \& Theios, J. (1982). Identification and pronunciation effects in a verbal reaction time task for words, pseudowords, and letters. Memory and Cognition, 10, 443-450. http://dx.doi.org/10.3758/BF03197646

Schaeffer, B., \& Wallace, R. (1969). Semantic similarity and the comparison of word meanings. Journal of Experimental Psychology: General, 82, 343-346. http://dx.doi.org/10.1037/h0028287

Schvaneveldt, R. W., \& Meyer, D. E. (1973). Retrieval and comparison processes in semantic memory. In S. Kornblum (Eds.), Attention and Performance (pp. 421-452). New York: Academic Press.

Seidenberg, M. S., Waters, G. S., Sanders, M., \& Langer, P. (1984). Pre-and postlexical loci of contextual effects on word recognition. Memory and Cognition, 12, 315-328. http://dx.doi.org/10.3758/BF03198291

Sternberg, S. (1969). The discovery of processing stages: Extensions of Donder's method. Acta Psychologica, 30, 276-315. http://dx.doi.org/10.1016/0001-6918(69)90055-9

Stroop, J. R. (1935): Studies of interference in serial verbal reactions. Journal of Experimental Psychology, 18, 643-662. http://dx.doi.org/10.1037/h0054651 